(Aus dem medicinisch-physikalischen Cabinet des Herrn Prof. Gruenhagen in Königsberg $i$. Pr.)

\title{
Der Humor aqueus des Auges in seinen Beziehungen zu Blutdruck und Nervenreizung.
}

\author{
Von
}

S. Jesmer, cand. med.

Seitdem Schwalbe ${ }^{1}$ ) durch den Nachweis offener Communicationen zwischen der vorderen Augenkammer und den vorderen Ciliarvenen der Anschauung Bahn gebrochen hatte, dass der ersteren die Bedeutung eines Lymphraums zuzusprechen, der humor aqueus folglich als Lymphe aufzufassen sei, sind dieser ursprïnglich auf rein anatomischen Grundlagen beruhenden Vorstellung bald auch physiologische Stïtzen erwachsen, und wäre wohl kaum ein nennenswerther Autor zu bezeichnen, welcher direct dieselbe bekämpft hätte, trotzdem die anatomischen Befunde Schwalbe's in Leber ${ }^{2}$ ) einen gewichtigen Gegner gefunden hatten.

Erst neuerdings ist durch Dogiel ${ }^{3}$ ) die Identificirung des humor aqueus mit Lymphe als unzulässig bezeichnet worden, und zwar desshalb, weil die Differenzen in der chemischen Zusammensetzung beider Flüssigkeiten allzu erheblich wären. Gleichzeitig theilt Dogiel aber anch die Ergebnisse seiner Untersuchungen uiber die Abhängigkeit der im Kammerwasser ausgeschiedenen Eiweissmenge rom Blutdrucke mit und gelangt dabei zu dem Schlusse, dass ein Abhängigkeitsverhältniss fehTe. Da indessen andere Antoren hieriber zu ganz abweichenden Angaben gelangt sind, die Dogiel'schen Versuche ausserdem kaum als massgebend für die Entscheidung dieser Frage angesehen werden können, habe ich dieselbe in etwas erweiterter Fassung einer erneuten Prüfung un-

1) G. Schwalbe, Max Schultze's Archiv f. microscop. Anatomie 1870 Band VI pag. I und 261.

2) Leber, Archiv für Ophthalmologie, Band XIX Abtheil. 2 pag. 87.

3) D ogiel, Pflüger's Archiv f. Physiologie 1879 Band XIX pag. 335. 
Der H. aqueus d. Auges i. seinen Beziehungen z. Blutdruck u. Nervenreizung. 15

terzogen und daran die Erörterung einiger neuen mir aufgefallenen Erscheinungen angeschlossen. Bevor ich jedoch hierauf näher eingehe, halte ich es für zweckmässig dem Fundament der ganzen Frage, der chemischen Beschaffenheit des humor aqueus, eine kurze Betrachtung zu widmen und die eigenen Wahrnehmungen zu schildern, welche von mir in Betreff seines Eiweiss-, Fibrinund Zuckergehalts gewonnen worden sind.

\section{Eiweissgehalt.}

Der normale h. a. enthält stets Eiweiss, wie dieses schon früher mehrfach von anderen Autoren hervorgehoben worden ist. Freilich ist die Quantität desselben nicht so bedeutend, wie diejenige der Armlymphe oder der Lymphe des ductus thoraciens, andererseits aber auch nicht so unerheblich, dass man das Eiweiss nicht ausnahmslos in Form einer flockigen Ausscheidung durch Erhitzen mit nachträglichem Zusatz von wenig Essigsäure nachzuweisen vermöchte. Wie Dogiel in seiner oben citirten Abhandlung behaupten kann, ihm wäre der Eiweissgehalt seiner grossen Geringfügigkeit halber fast entgangen, wenn er sich nicht nach einer empfindlicheren Eiweissprobe umgeseben und eine solche in der von Adamkiewicz beschriebenen Farbenreaction nach Znsatz von Eisessig and concentrirter Schwefelsäure zu eiweisshaltigen Flüssigkeiten gefunden hätte, ist mir unverständlich. Im h. a. sämmtlicher von mir untersuchten Augen, mochte derselbe nun dem lebenden oder dem todten Thiere entnommen sein, trat beim Erhitzen eine deutliche Trübung ein, welche sich bei Zusatz von kleinen Mengen Essigsäure zu einer feinflockigen Ausscheidung gestaltete. Noch sicherer und vollständiger gelingt es eine solche zu erhalten, wenn man, wie es übrigens in der vorliegenden Arbeit immer geschehen ist, den aufgefangenen h. a. durch Zusatz von Glaubersalz in Substanz in eine concentrirte Salzlösung: verwandelt, sodann mit Essigsäure ansäuert und nun erst vorsichtig erhitzt. Versuche den Eiweissgehalt des Kammerwassers mittelst des Wild'schen Polaristrobometers quantitativ zu bestimmen haben zu keinem directen Ergebniss geführt, aber wenigstens einen mittelbaren Aufschluss gegeben. Um über grössere Quantitäten des h. a., wie sie zur Füllung der Röhre des Polaristrobometers gebraucht werden, zu verftigen, bediente ich mich des in verhält- 
nissmässig beträchtlichen Mengen zu beschaffenden h. a. frischer Rindsaugen. Als letzterer in der $200 \mathrm{~mm}$ langen Röhre zwischen Polariskop and polarisirendem Nicol eingeschaltet wurde, blieb das im Natriumlicht erhellte Gesichtsfeld des Polaristrobometers ebenso frei von den charakteristischen Interferenzstreifen wie vor Einschaltung der zu prüfenden Flüssigkeit, d. h. dieselbe drehte den polarisirten Lichtstrahl gar nicht. Es wäre verfehlt hieraus den Schluss zu ziehen, dass die Eiweissmenge der wässrigen Flïssigkeit des Rindes keine merkliche Wirkung auf den polarisirten Lichtstrahl ausübe. Wissen wir doch seit den Untersuchungen von Chabbas ${ }^{1}$, dass der frische $h$. a. vieler Thiere normaler Weise Zucker enthält, und gilt das gleiche, wie ich auf Grund eigener Erfahrung schon jetzt mittheilen will, auch für den h. a. des Rindes. Da Zucker und Eiweiss die Polarisationsebene aber im entgegengesetzten Sinne drehen, so begreift sich, warum die gefundene optische Unwirksamkeit des Kammerwassers das Vorhandensein von merklichen Quantitäten optisch wirksamer Substanzen noch keineswegs auszuschliessen braucht. Fassen wir diese Möglichkeit aber ins Auge, so bietet sich auch zugleich ein doppelter Weg die Eiweissmenge des Kammerwassers quantitativ durch den Polarisationsapparat zu ermitteln: erstens ein directer, welcher darauf hinausliefe den rechtsdrehenden Zucker zu entfernen und dann die Untersuchung mit dem Polaristrobometer zu wiederholen, zweitens ein indirecter, welcher zum Zielpunkt hätte gerade umgekehrt das links drehende Eiweiss auszufällen und sich nachträglich von der Menge des übriggebliebenen rechtsdrehenden Zuckers zu unterrichten.

Es bedarf keiner weiteren Auseinandersetzung, dass das zweite indirecte Verfahren grössere technische Bequemlichkeiten bietet als das erste directe, und wirklich ist denn auch nur jenes von mir eingeschlagen worden. Ich entfernte demgemäss das Eiweiss nach der früher beschriebenen Methode aus dem Kammerwasser, brachte dieses dann in die $200 \mathrm{~mm}$ lange Röhre des Polaristrobometers und konnte nun in der That einen Zuckergehalt von $0,16-0,2 \%$ constatiren. Hätten nun Eiweiss und Zu-

1) Chabbas, Pflüger's Arch. 1877, Bd. XVI p. 143. Ueber die Secretion d. h. a. in Bezug auf die Frage nach d. Orsachen d. Lymphbildung. Dissertat. Königsberg 1878. 
cker einen nahezu gleichen Drehungswinkel, wie es in der That wenigstens für Serumalbumin der Fall ist, so würde aus dem mitgetheilten Ergebniss indirect ein gleicher Procentgehalt von Serumalbumin im h. a. zu erschliessen sein. Die absolute in dem h. a. des Rindsauges auffindbare Eiweissmenge ist also jedenfalls beträchtlich geringer als die in der Lymphe des ductus thoracicus aufgelöste. Man würde jedoch irre gehen, wenn man hieraus folgern wollte, dass der h. a. keine Lymphe sein könne. Denn der Eiweissgehalt der Lymphe unterliegt sicher je nach dem Orte ihrer Entstehung sehr erheblichen Schwankungen, und uiberdies kennen wir noch andere Flüssigkeiten innerhalb des thierischen und menschlichen Körpers, welche zweifellos als Lymphabsonderungen anzusehen, dabei aber ebenso arm an Eiweiss sind wie der h. a. Dahin gehört vor allem die cerebrospinale Flüssigkeit, deren Lymphnatur anatomiseh längst ausser Zweifel gestellt ist.

\section{Fibringehalt.}

Abweichend von den meisten Flüssigkeiten, die zur Kategorie der Lymphflüssigkeiten gezählt werden, zeigt der h. a. des vollkommen normalen Anges, selbst wenn man ihn aus der vorderen Augenkammer entfernt, keine Gerinnselbildung. Es würde dieses wohl gegen die Ansicht, dass h. a. und Lymphe identisch seien, sehr ins Gewicht fallen, wenn nicht auch hierin der h. a. ein Analogon in der cerebrospinalen Flüssigkeit hätte, welche ungeachtet ibrer unbestreitbaren Lymphnatur ebenfalls keine Gerinnungsfähigkeit besitzt. Es kann demnach das Fibrin nicht als constanter Bestandtheil der Lymphe angesehen werden, und ist damit wohl auch dieser Einwand gegen die Identität des h. a. mit der Lymphe beseitigt. Im Einklange mit der Unfähigkeit des normalen Kammerwassers zu gerinnen steht, dass sich in demselben anch durch die empfindlichste uns zu Gebote stehende Probe kein Fibrinferment nachweisen lässt. Eine solehe Probe stellt bekanntlich das Wasserstoffsuperoxyd dar, welches sich bei Gegenwart verschiedenartiger Fermente und auch des Fibrinferments sofort unter Freiwerden von Sauerstoff zersetzt. Um eine möglichst concentrirte Lösung des genannten Reagens zu erhalten, leitet man der Vorschrift A. Sehmidt's gemäss während mehrerer Stun- 
den einen Kohlensäurestrom durch Baryumsuperoxyd, welches, in destillirtes Wasser eingetragen, unter den bezeichneten Umständen unlöslichen kohlensauren Baryt und lösliches Wasserstoffsuperoxyd liefert. Setzt man nun eine ganz geringe Quantität Blut oder irgend eine andere fermenthaltige Flisssigkeit zu der vom Bodensatz abgegossenen Wasserstoffsuperoxydlösung zu, so beginnt sofort durch Zersetzung von Wasserstoffsuperoxyd eine Entwicklung von Sauerstoffgas, welches in kleinen Bläschen in der Flüssigkeit in die Höhe steigt, niemals dagegen bei Zusatz von normalem $h$. a., welcher demnach gänzlich frei von Ferment sein dürfte. Jedoch nicht nur das Fibrinferment, auch die anderen zum Zustandekommen einer Fibrinbildung nöthigen Stoffe, die fibrinogene und fibrinoplastische Substanz, fehlen dem h. a., da derselbe selbst dann kein Fibrincoagulum bildet, wenn man ihn mit etwas Blut und folglich auch mit Fibrinferment versetzt. Es ist demnach nicht allein der Mangel an Ferment, sondern die Abwesenheit aller Fibringeneratoren überhaupt als die Ursache der fehlenden Gerinnungsfähigkeit anzusehen. Jedoch gilt dieses alles nur von der unter normalen Verhälthissen ausgeschiedenen wässrigen Feuchtigkeit des Auges. Werden die Druckverhältnisse im Auge, etwa durch Herabsetzung des Drucks in der vorderen Kammer geändert, oder die Fluxion zum Auge durch Dilatation der Gefässe gesteigert, so tritt bei Thieren wenigstens sofort eine Ausscheidung aller Fibringeneratoren in der vorderen Kammer ein, der unter solchen Verhältnissen secernirte h. a. gerinnt, sobald er dem Auge entnommen ist. Bemerken will ich hierbei, dass die Entleerung: des h. a. behufs Bestimmung seines Fibringehalts stets nach dem Tode des Thieres vorgenommen wurde, um die Möglichleit einer Aspiration von Blut bei der Entnahme des Inhalts der vorderen Augenkammer, wozu stets eine Pravaz'sche Spritze mit feiner Holzhauer'scher Stahlcantile gebrancht wurde, auszuschliessen. Ebenso wie Herabsetzung des Drucks in der vorderen Augenkammer wirkt vermehrte Fluxion resp. Dilatation der Gefässe, welche man besonders leicht durch Reizung des Corneoscleralrandes erzielen kann. Aetzt man die Augen von Kaninchen oder Katzen am Corneosleralrande mit Höllenstein in Substanz und tödtet daun das Thier nach ca. 1/2-1 Stunde durch Nackenstich oder Chloroforminhalationen, so findet man in dem der vorderen Kammer des todten Thieres entnommenen h. a. stets massenhaft Fibrin, so dass 
Der H. aqueus d. Auges i. seinen Beziehungen z. Blutdruck u. Nervenreizung. 19

derselbe zu einer festen Masse gerinnt. - Auf die Abhängigkeit der Fibrinproduction von rein nervösen Einflüssen, insbesondere vom Trigeminus, komme ich bei einer anderen Gelegenheit zurück.

Hinzufügen will ich noch, dass bei allen Eingriffen, welche Fibrinausscheidung zur Folge hatten, der h. a. nie gerann, so lange er in der vollkommen normalen vorderen Augenkammer verblieb. Es ergiebt sich hieraus, dass den Wandungen der letzteren derselbe gerinnungshemmende Einfluss wie denjenigen der lebenden Blat- und Lymphgefässe inwohnt, ein Moment mehr offenbar, welches zu Gunsten der Auffassung ins Gewicht fällt, dass die vordere Augenkammer die Bedeutung eines Lymphraums besitze.

\section{Zuckergehalt.}

Die ersten Angaben über Zucker im h. a. sind, soweit meine literarischen Nachforschungen reichen, von Chabbas in den oben citirten Abhandlungen gemacht worden. Vorher hat zwar schon Deutschmann ${ }^{1}$ ) im Auge eines Diabetischen Zucker nachgewiesen, diesem Befund jedoch eine pathologische Bedeutung zugeschrieben, indem er ihn auf den bestehenden Diabetes zurïckführte. Chabbas fand im h. a. von Kaninchen, Hunden und Katzen stets Zucker, aber nur einmal beim Rinde; ich kann diese Angaben erheblich erweitern, insofern es mir gelungen ist ausser bei Kaninchen, Hunden und Katzen auch im h. a. der Rinder-, Hammelund Schweineaugen die Anwesenheit von Zucker nachzuweisen, vorausgesetzt nur, dass ich über ganz frische Augen zu verfügen hatte. Das abweichende Ergebniss der Ermittelungen von Chabbas wird, soweit die Untersuchungen sich auf wirklich frische Augen erstreckten, wohl auf Ungenarigkeiten in der Anstellung. der von ihm und anch von mir in Gebrauch gezogenen Trom$\mathrm{m}$ er'schen Zuckerprobe beruhen.

In der That handelt es sich hier um so geringe Quantitäten, - es wurden noch Zuckerproben mit 0,3 cem h. a., deren Zuckergehalt also ungefähr 0,006 gr beträgt, angestellt, - dass man mit dem Zusatz des Kupfersalzes und des Kali nicht aufmerksam genug verfabren kann. So ist auch mir im Beginne meiner Unter-

1) Deutschmann, v. Graefe's Archiv f. Ophthalm. 1877 Band XXIII Theil 3 p. 143. 
suchungen manche Probe misslungen, später aber, als ich über die erforderlichen Zusatzmengen unterrichtet war, fast niemals.

Ganz besondere Vorsicht erheischt namentlich der Zusatz des Kalihydrats. Ist die Quantität desselben zu gross, so entfärbt sich zwar die lichtblane Flüssigkeit beim Erwärmen, es kommt indessen zu keiner gelbgefärbten Ausfällung, bis eine vorsichtige Ansänerung mit Essig- oder Salzsäure die Ausscheidung des durch Kaliüberschuss in Lösung erhaltenen Kupferoxyduls bewirkt und jeden Zweifel an der Positivität des Reactionsergebnisses beseitigt. Ich habe im Ganzen c. 160 Thieraugen auf Zuckergehalt im h.a. untersucht, darunter nur $15 \mathrm{mal}$ negative Resultate und diese letzteren beinahe sämmtlich in der ersten Zeit meiner Arbeit erhalten. Ausser der Trommer'schen Zuckerprobe habe ich mich mitunter auch der von Sachsse empfohlenen Jodkali-Jodquecksilberlösung bedient, jedoch bald eingesehen, dass dieselbe zum sicheren Nachweise soleh' kleiner Zuckerquantitäten, wie sie hier in Frage kommen, nicht ausreicht, und es ausserdem schwieriger ist, Ausfällungen von granem Quecksilber- als von gelbem Kupferoxydul zu erkennen. Um den negativen Ausfall der Trommerschen Probe zu erklären, welcher für den h. a. der Wiederkäueraugen die Regel bildete, hat Chabbas angenommen, dass die vor dem Schlachten gewöhnlich längere Zeit ohne Nahrung erhaltenen Thiere sich im Hungerzustande befunden hätten, während desselben aber der Zucker im h. a. verschwände.

Hieran ist richtig, dass der Hunger allerdings den von Chabbas angezeigten Einfluss auf die chemische Zusammensetzung des h. a. ausübt; wenigstens vermisste auch ich den Zucker im Kammerwasser bei Kaninchen, welche 36-48 Stunden vor dem Tode gehungert hatten; nicht richtig dagegen ist, dass das Hungern bei den Sehlachthofthieren eine Rolle gespielt haben kann, da meine Untersuchungen, wie oben mitgetheilt, im geraden Gegensatze zu Chabbas der Regel nach zu positiven Ergebnissen hinsichtlich des Zuckergehalts führten.

Dass diese Kupferoxyd reducirende Substanz Zucker ist, hat schon Chabbas durch die Gährungsprobe nachgewiesen, ich möchte nur noch hinzufuigen, dass auch die im liquor cerebrospinalis befindliche reducirende Substanz die Gährungsprobe giebt, also Zucker ist, was von Hoppe geleugnet wird. Man muss bei der Anstellung der Gährungsprobe nur nicht vergessen, die alka- 
Der H. aqueus d. Anges i. seinen Beziehungen z. Blutdruck u. Nervenreizung. 21

lisch reagirende cerebrospinale Flüssigkeit zu neutralisiren und, wenn trotzdem die Kohlensäureentwicklung ausbleibt, sich damit genügen lassen, dass die vor Hinzufügung der Hefe gelingende Trommer'sche Probe nach mehrstuindigem Contact der betreffenden Lösung mit den Hefepilzen stets fehlschlägt. Es ist eben sehr leicht möglich, dass die bei dem spärlichen Gehalt der cerebrospinalen Flüssigkeit an Zucker bei der Gährung in so geringer Menge sich entwickelnde Kohlensäure in Lösung erhalten wird.

Diese positiven Resultate bei der Untersuchung des h. a. auf Zucker erhält man aber nur, wenn man die Probe mit dem bald nach dem Tode des Thieres dem Auge entnommenen Kammerwasser anstellt. Entleert man den h.a. erst 24-48 Stunden nach dem Tode oder überlässt man das frisch herausgenommene, vor Vertrocknung aber gesicherte Auge c. 24-48 Stunden sich selbst und stellt dann erst die Zuckerprobe mit dem h.a. an, so erhält man ein negatives Resultat. Es fiel mir dieses auf, so oft ich Rindsaugen vor der Untersuchung einen Tag liegen gelassen hatte, und konnte ich da nur an ein Verschwinden des Zuckers nach dem Tode denken. Um dieser Vermuthung eine positive Grundlage zu geben, stellte ich jedoch noch folgende Versuche an:

1) Von einer grösseren Anzahl frischer Augen wurde den einen sogleich der h. a. entnommen, den anderen nach $24-48$ Stunden.

2) Von den Augen desselben Thieres wurde das eine sofort nach dem Tode, das andere c. 24-48 Stunden später entleert. Untersucht wurden in dieser Art Rinds-, Kaninchenund Katzenaugen.

3) Es wurde aus der vorderen Kammer von Rinds- und Katzenaugen durch eine Pravaz'sche mit einer feinen (Holzhauerschen) Stahlcanüle versehenen Spritze so viel h. a. aufgesogen, als zur Anstellung einer Zúckerprobe genügte, der grössere Theil aber darin gelassen und 24-48 Stunden später entleert und untersucht.

4) Es wurde die vordere Kammer frischer Augen nach Entleerung des h.a. mit einer verdünnten Traubenzuckerlösung gefüllt und letztere 24 Stunden später behufs Anstellung der Trommer'schen Probe wieder entleert. Wenn sich die absichtlich möglichst schräg angelegte Stichwunde der Cornea nicht sogleich von selbst durch Aneinanderlegen der Wan- 
dungen schloss, wurde das Ausfliessen des Inhalts durch Einlegen eines feinen Glasstäbchens verhütet.

Alle diese Versuche fïhrten stets zu dem übereinstimmenden Ergebniss, dass ein postmortales Verschwinden von Zucker aus der vorderen Kammer stattfindet, da nach 24stündigem Verweilen der natürlichen oder künstlichen zuckerhaltigen Lösungen im Ange die Trommer'sche Probe entweder ganz resultatlos blieb, oder durch die unverkennbar geringer gewordene Ausfällung von Kupferoxydul doch auf eine beträchtliche Verminderung des Zuckergehalts schliessen liess.

Um jedem Missverständnisse vorzubengen, muss indessen noch ausdruicklich betont werden, dass der Zuckerschwund nur in dem mit dem Bulbusinnern in Berïhrung gebliebenen h. a. vor sich geht, in dem entleerten und für sich allein aufbewahrten h.a. findet ein solcher dagegen niemals statt.

Bei dieser Gelegenheit will ich noch erwähnen, dass ich wiederholt den Glaskörper von Rinds- und Kaninchenaugen auf Zucker untersucht und ebenfalls stets zuckerhaltig befunden habe. Ausserdem zeigt der Zucker des Glaskörpers, ebenso wie derjenige des h. a., die Eigenthïmlichkeit zu versehwinden, sobald das corpus vitreum längere Zeit nach dem Tode im Bulbus zurückbleibt. Es giebt daher die Trommer'sche Probe regelmässig ein negatives Resultat, wenn man dieselbe mit einer dem Auge 24 Stunden post mortem entnommenen Glaskörperflüssigkeit anstellt.

Abhängigkeit des Eiweissgebaltes vom Blutdruck.

Die ersten Angaben über eine zwischen Blutdruck und Eiweissgehalt des Kammerwassers bestehende Beziehung rïhren von A dami $\mathrm{ck}^{1}$ ) her, sind aber mehr beiläufiger Natur. Seinen Befunden gemäss hätte eine Steigerung des Blutdrucks auch eine solche der Eiweissausscheidung im h. a. zur Folge. Hierauf folgten die viel bestimmteren Angaben der Chabbas'schen Arbeit, die im Wesentlichen mit den Adamü ck'schen übereinstimmen. Endlich hat Dogiel in seiner fruher citirten Abhandlung, und zwar mit Hinblick auf die Chabbas'sche Mittheilung, die gleiche Frage behandelt, dabei aber ganz entgegengesetzte Ergebnisse erzielt.

1) Wiener Sitzungsberichte 1869. Mth,-ntw. Cl. Abtheil. II. Bd. LIX. 
Der H. aqueus d. Auges i, seinen Beziehungen z. Blutdruck u. Nervenreizung. 23

Indem er die von Adamkiewicz beschriebene Farbenreaction des Albumins nach Zusatz von concentrirter Schwefelsäure und Fisessig zum qualitativen und quantitativen Nachweis des im Kammerwasser vorhandenen Eiweisses verwerthete, gelangte er dahin, jedwede Abbängigkeit der Menge des letzteren rom Blutdrucke in Abrede zu stellen. Dieser Widerspruch der Meinungen war es denn, welcher mich veranlasste, der ganzen Frage auf's neve näher zu treten, und will ich gleich hier voransehicken, dass das Ergebniss meiner Versuohe den Aussprüchen Dogiel's ungünstig ausgefallen ist, dagegen mit den Angaben von Adamiück und Chabbas im Ganzen übereinstimmend lautet.

Was die negativen Resultate Dogiel's betrifft, so glaube ich, dass dieselben durch das von ihm eingeschlagene Versuchsverfahren bedingt sind, da diesem für die Beantwortung der Frage, ob der Eiweissgehalt des h. a. vom Blutdrucke abhängig sei oder nicht, keine maassgebende Bedeutung inwohnt. Denn offenbar kommt es zur Lösung des hier angeregten Problems weniger darauf an Versuche anzustellen, bei welchen der gesammte intraoculäre Blutdruck durch gesteigerte Blutzufuhr erhöht wird, wie von Dogiel geschehen, als solche, bei welchen die Differenz zwischen intraoculärem Blutdruck und Spannung der Bulbuscontenta einer Aenderung unterworfen wird, weil ja doch bei allen Filtrationsprocessen, und als ein solcher ist die Secretion des $h . a$. jedenfalls aufzufassen, lediglich das Vorhandensein einer Druckdifferenz und die Grösse derselben von Bedeutung ist. Erhöht man aber mit Dogiel den Blutdruck innerhalb des Bulbus z. B. durch Unterbindung der Aorta descendens, so nimmt zwar die Spannung des Bulbus, wie schon früher v. Hippel und Grünhagen ${ }^{1}$ ) und Adamü ck bewiesen haben, augenblicklich durch Anschwellen der mitBlut überfüllten Chorioidealgefässe $z u$, dieses ïbt aber auf den zwischen Blutgefäss- und Augeninhalt bestehenden Druckunterschied, die Hauptbedingung für die Ausscheidung des h. a. keinen irgendwie in Betracht kommenden Einfluss aus.

Versuche derart, wie sie ron Dogiel ausgeführt sind, können also zur Entscheidung der in Rede stehenden Frage nichts beitragen. Dazu bedarf es besonderer Vorkehrungen, welche es

1) Archiv f. Ophthalmol. 1868 Bd. XIV Abth. 3 pag. 214 und 1869 Bd. XV Abth. 2 pag. 265. 
ermöglichen, die in der vorderen Augenkammer herrschende Spannung constant auf gleicher Höhe zu erhalten, während der Seitendruck des Blutes in den Augengefässen innerhalb bestimmter Grenzen erhöht oder herabgesetzt wird; dass Do giel sich solcher Vorkehrungen bedient hätte, wird nirgends von ihm erwähnt und ist wohl auch nicht anzunehmen. Mittel und Wege, den gestellten Anforderungen zu geniigen, giebt es indessen mehrere. So könnte man z. B. die vordere Augenkammer mit einem Quecksilbermanometer in Verbindung bringen, welches dem normalen Augendrucke gerade das Gleichgewicht hält, und nun erst die Erhöhung des Blutdrucks mittelst der bekannten von Dogiel in Anwendung gezogenen Eingriffe hervorrufen. Empfehlenswerth ist es jedoch, den umgekehrten Weg einzuschlagen und, wie von mir geschehen, den Blutdruck unverändert zu lassen, dagegen den Druck in der vorderen Augenkammer um eine bestimmte Grösse herabzusetzen beziehungsweise zı erhöhen und während der ganzen Dauer des Versuchs ununterbrochen auf derselben Höhe zu erhalten.

Es bietet dieses Verfahren, bei welchem jede Art von Druckdifferenz hergestellt werden kann, mancherlei Vortheile. Erstens ist der operative Eingriff, welcher mit demselben verknüpft ist, ein verhältnissmässig geringer, da alle auf Erhöhung des Blutdrucks abzielenden Manipulationen, welche zum Theil, wie die Aortenunterbindung, Reizung des oberen Halsmarks den normalen Ablauf der Lebensprozesse auf das Erheblichste beeinträchtigen, zum Theil, wie die Durchschneidung des Halssympathicus, Reizung peripherer sensibler Nerven von zu schwacher und namentlich zu wenig dauerhafter Wirkung sind, vollständig fortfallen. Zweitens ist hier aber anch der Grad der erzeugten Druckdifferenz leichter zu messen und durch Zahlen auszudrïcken, während die bei Erhöhung des Blutdrucks im Aortensystem innerhalb der Augengefüsse stattfindende Druckzunahme sich einer genauen Schätzung so gut wie vollständig entzieht, und drittens endlich ist das von mir berorzugte und ausschliesslich in Anwendung gebrachte Verfahren ausgezeichnet durch die Leichtigkeit, mit der sich dasselbe handhaben lässt. Handelt es sich doch nur um die keineswegs schwierige Einführung einer mit einer Glasröhre in Verbindung stehenden Stichcaniule in die vordere Augenkammer.

Die grösste Druckdifferenz erhält man nun nach der von mir geübten Methode, wenn man die vordere Kammer nnter Null- 
Druck setzt, d, h. eine feine in ein horizontales Glasrohr auslaufende Stahlcanüle in die Cornea einstösst und dem $h$. a. freien Abfluss in ein kleines Sammelgefäss gestattet. Um aber nicht nur den unter Nulldruck sondern auch den unter anderen beliebig zu bestimmenden Druckwerthen secernirten h. a. mit dem unter normalen Druckverhältnissen ausgeschiedenen vergleichen zu können, modificirte ich die oben beschriebene Einstichscanüle mit dem horizontalen Glasrohr dahin, dass ich das letztere zwei mal unter einem rechten Winkel bog, ihm damit die Gestalt eines Winkelmaasses ertheilte, dessen beide horizontalen, nach entgegengesetzten Seiten auslaufenden, kurzen Schenkel durch ein längeres vertical aufsteigendes Mittelstiick unter einander verbunden waren. Von solchen Apparaten wurden mehrere angefertigt, welche sich von einander nur durch die grössere oder geringere Länge des senkrechten Steigrohrs unterschieden. Vor jedem Versuche wurde durch eine an dem oberen horizontalen Schenkel befestigte Kautschuckröhre Wasser bis zum oberen Biegungspunkte des Steigrohrs aufgesogen, das Ausfliessen der Flüssigkeit durch Anlegung einer Serrefine an dem Kautschuckrohr verhindert. Nach Einfuihrung der Stahleaniule des Instruments in die vordere Kammer wurde die Serrefine abgenommen, und es stellte dann die Wassersäule des Steigrohrs die immer constant bleibende Druckhöhe dar, unter welcher sich die vordere Augenkammer während der nun stattfindenden Secretion des h. a. befand. Sollte der Versuch nach Ablauf einer genau bestimmten Zeit beendet werden, so wurde die Serrefine wieder angelegt, und dann erst die Spitze des Apparats aus dem Auge herausgezogen. Es mussten dann die Stahleaniule und die tieferen Abschnitte des (verticalen) gläsernen Abflussrohrs mit h. a. gefüllt sein, welcher unter einem je nach der von mir gewählten Höhe des Verticalrohrs verschiedenen subnormalen oder selbst supranormalen Druck in der vorderen Augenkammer secernirt war. Letzterer beträgt normal nach den ziemlich übereinstimmenden Angaben v. Hippel's, Grünhagen's und Adamück's durehschnittlich $22 \mathrm{~mm}$ Quecksilber oder 29,7 cm Wasser. Ich benutzte zu meinen Versuchen Röhren von 7,5, 20, $40 \mathrm{~cm}$ Höhe; es befand sich die vordere Kammer also nur bei Anwendung der letzten der drei Ausflussröhren unter einem supranormalen Druck. In diesem Falle stand folglich beim Oeffnen der Serrefine an dem Kautschuckende des oberen horizontalen Schenkels ein Sinken der Flüssigkeit 
im verticalen Rohre zu erwarten, während in der Versuchsreihe mit den niedrigen Steigröhren die Wassersäule emporgehoben werden und in den oberen horizontalen Schenkel ïberlanfen musste, zugleich aber auch in der Schnelligkeit und Weite ihres Vorrickens ein Maass sowohl für die Geschwindigkeit als auch für die Menge des secernirten Kammerwassers gewährte.

Wie schon friber bemerkt, nimmt der ausgeschiedene h. a. stets die untersten, der Canüle am nächsten gelegenen Absehnitte des Abflussrohres ein und kann in nahezu reinem d. h. unverdünntem Zustande gewonnen werden, wenn man das bei der Entfernung der Einstichscanüle aus der vorderen Kammer stets zu schliessende Gummirohr am Ausflussende des Apparats wieder öffnet und soviel von dem fliussigen Inhalt durch die Oeffnung der Stahleanüle abträufeln lässt oder ansbläst, bis die Wassersäule auf das Niveau. des Versuchsbeginnes angelangt ist. Die in der vorderen Kammer zurückgebliebene Menge entleerte ich mittelst einer Pravaz'schen Spritze.

Was nun die Wahl der Versuchsthiere betrifft, so kann ich, wenn man die Versuche absolut rein haben will, besonders Katzen empfehlen, bei denen das Einführen der Canüle als ein Eingriff von höchst unbedeutender Reizwirkung angesehen werden darf. Bei Kaninchen besteht ein so günstiges Verhältniss nicht, da bei ihnen merkliche Reizerscheinungen am Auge fast niemals ausbleiben. Letztere sind aber auf den Eiweissgehalt des h. a. von bedeutendem Einflasse, da dieser gerade so wie der Gehalt an Fibrin in Folge mechanischer oder chemischer Reizung der Cornea zunimmt. Energische Aetzung der Hornhaut am Scleralrande mittelst eines Höllensteinstiftes bedingt daher bei Kaninchen und Katzen zugleich mit der Ausscheidung der Fibringeneratoren auch eine Vermehrung des Eiweisses im Kammerwasser, und zwar auf dem gleichen Wege, anf dem meiner Ansicht nach die Bedingungen der Fibrinproduction herbeigeführt werden, d. h. durch Reizung gefässdilatirender Nerven des Auges. Für meine Versuche folgt hieraus, dass die Einführung der Stahlcanïle in die vordere Kammer an und für sich schon als mechanisches Reizmoment 'einen modificirenden Einfluss auf die chemische Beschaffenheit des h. a. auszuuiben vermag. Damit ist jedoch nicht gesagt, dass dieser Eingriff für die von mir verfolgten Zwecke unzulässig sei. Denn einerseits ist die durch Einführung der Canüle ausgeübte Reizung niemals 
Der H. aqueus d. Auges i. seinen Beziehungen z. Blutdruck u. Nervenreizung. 27

auch nur annähernd so stark wie die chemische durch Anätzen des Scleralrandes der Cornea hervorgerufene, andererseits ist aber auch die durch Einführung der Canüle bewirkte Eiweissvermehrung: bei allen angestellten Versuchen die gleiche; ist also in diesem Falle, wo es sich nicht um Bestimmung des absoluten, sondern des relativen Eiweissgehalts handelt, für die etwaigen aus den Versuchsergebnissen zu ziehenden Schlüsse von keinem Einflusse. Somit können auch Kaninchen trotz der grössern Reizbarkeit ihrer Augen zu Versuchen, wie sie die vorliegende Arbeit bringt, benutzt werden.

Was nun die Methode zur Bestimmung der Eiweissmenge anlangt, so habe ich hier ebenso wenig wie zum Nachweise des Eiweisses im h. a. überhaupt die von Dogiel benutzte Adamkiewicz'sche Probe nöthig gehabt, sondern bin jederzeit mit der vergleichsweisen Schätzung der durch Kochen des h. a. in einer angesüuerten Glaubersalzlösung entstehenden Trübungen und Ausfällungen ausgekommen. Ja mir scheint es, wenn ich nach den Ergebnissen der Dogiel'schen Untersuchungen urtheilen soll, iiberhaupt noch zweifelhaft, ob die von ihm angewandte Probe sich ausser zum qualitativen Nachweis ron Eiweiss auch zur quantitativen Bestimmung desselben eignet, d. h., ob die Farbennuancen für die Menge des Eiweisses wirklich so characteristisch sind. Wenigstens kann ich mir z. B. nur aus der Unzulänglichkeit der Probe den auffallenden Ausspruch Dogiel's erklären, dass der Eiweissgehalt des Glaskörpers ein verschwindend kleiner sei und von dem des h. a. bedeutend übertroffen werde, während Deutsch$\operatorname{mann}{ }^{1}$ ), dem ich übrigens ganz beipflichte, doch schon fruher die Unrichtigkeit dieser bereits von Lohmeyer aufgestellten Behauptung bewiesen und den starken, denjenigen des h. a. bei weitem uibertreffenden Eiweissgehalt des Glaskörpers dargethan hat. Das von mir eingeschlagene Verfahren hat sich, so ungenau es auch ist, wenn es gilt geringe Differenzen der Eiweissausscheidung festzustellen, bei den sehr grossen Differenzen, mit welchen ich es hier zu thun hatte, als vollkommen ausreichend erwiesen.

Dies voraus gesehickt lasse ich nunmehr die Protocolle eines grossen Theils der zu dem in Rede stehenden Zweck angestellten Versuche folgen, und bemerke nur noch, dass alle meine Versuchsthiere durch Curare bewegungslos gemacht wurden.

1) Deutschmann, Graefe's Archiv f. Opht. 1879. Bd. XXV. Abth. 1. 


\section{Versuch.}

Sehr grosse Katze; Injection von $1 \mathrm{ccm}$ der vorräthigen Curarelösung in die vena jugularis externa dextra; künstliche Athmung; Einführung der Canüle ins rechte Auge. Wasserdruck $20 \mathrm{~cm}$.

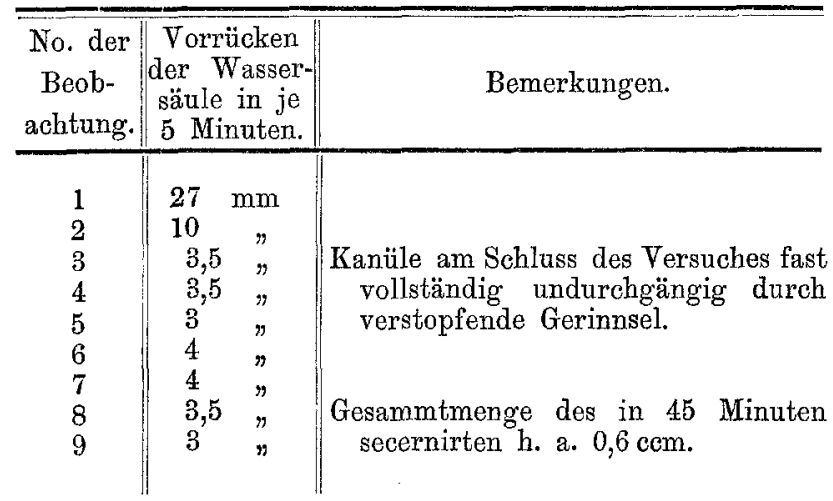

Der in einem kleinen gläsernen Standglas aufbewahrte h. a. erwies sich nach 24stündigem Stehen durch und durch geronnen. Das nach Loslösung von der Wandung erheblich schrumpfende Gerinnsel wird mittelst eines feinen Drahtes gänzlich entfernt. Der so defibrinirte Rest des h. a. zeigte einen die Norm erheblich übersteigenden Eiweissgehalt. Zuckergehalt wie gewöhnlich.

\section{Vers u eh.}

Grosse Katze, mit 1 ccm Curarelösung vergiftet. Einführung der Canüle ins linke Auge. Wasserdruck $7,5 \mathrm{~cm}$.

\begin{tabular}{|c|c|c|}
\hline $\begin{array}{l}\text { No. der } \\
\text { Beob- } \\
\text { achtung. }\end{array}$ & $\begin{array}{l}\text { Vorrücken } \\
\text { der Wasser- } \\
\text { säule in } \\
1 \text { Minute. }\end{array}$ & Bemerkungen. \\
\hline $\begin{array}{r}1 \\
2 \\
3 \\
4 \\
5 \\
6 \\
7 \\
8 \\
9 \\
10 \\
11\end{array}$ & $\begin{array}{cc}50 & \mathrm{~mm} \\
27 & \\
15,5 & " \\
16 & " \\
12 & " \\
12 & " \\
9 & " \\
11 & " \\
9,5 & " \\
9,5 & " \\
9,5 & "\end{array}$ & $\begin{array}{l}\text { Kanüle am Schluss des Versuchs durch } \\
\text { Gerinnsel fast ganz verstopft. } \\
\text { Gesammtmenge des in } 11 \text { Minuten } \\
\text { secernirten h. a.: } 1,8 \mathrm{ccm} \text {. }\end{array}$ \\
\hline
\end{tabular}

Die Untersuchung des secernirten h. a. nach 24stündigem Stehen ergiebt: sehr reichliche Gerinnselbildung, Eiweiss in der defibrinirten Flüssigkeit noch bedentend mehr als im vorigen Versuch, Zucker. 
Der H. aqueus d. Auges i. seinen Beziehungen z. Blutdruck u. Nervenreizung. 29

\section{Vers u ch.}

Grosse Katze, mit $0,8 \mathrm{ccm}$ Curarelösung vergiftet. Einführung der Canüle ins linke Auge. Wasserdruck $40 \mathrm{~cm}$ (supranormal). Nach Entfernung der Serrefine tritt ein allmäliches Sinken der Wassersäule ein.

\begin{tabular}{|c|c|c|}
\hline $\begin{array}{c}\text { No. der } \\
\text { Beob- } \\
\text { achtung. }\end{array}$ & $\begin{array}{l}\text { Sinken der } \\
\text { Wassersäule } \\
\text { in der Röhre } \\
\text { in je } 5 \text { Min. }\end{array}$ & Bemerkungen. \\
\hline $\begin{array}{l}1 \\
2 \\
3 \\
4 \\
5 \\
6\end{array}$ & $\begin{array}{l}3 \mathrm{~mm} \\
4 \% \\
4\end{array}$ & $\begin{array}{l}\text { Das Auge bleibt frei von allen Reiz- } \\
\text { erscheinungen. Unterbrechung des } \\
\text { Versuchs nach } 30 \text { Minuten. Der } \\
\text { Inhalt der vordern Kammer wird } \\
\text { nach dem Tode entnommen. }\end{array}$ \\
\hline
\end{tabular}

Die Untersuchung des entleerten Kammer-Inhalts ergiebt nach 24stïndigem Stehen: Kein Gerinnsel; äusserst wenig Eiweiss (subnormal), Zucker.

IV. Versuch.

Kleines Kaninchen $0,15 \mathrm{~cm}$ Curarelösung in die vena jugularis externa sinistra injicirt. Einführung der Canüle ins linke Auge. Wasserdruck $20 \mathrm{~cm}$.

\begin{tabular}{|c|c|c|}
\hline $\begin{array}{l}\text { No. der } \\
\text { Beob- } \\
\text { achtung. }\end{array}$ & $\mid \begin{array}{l}\text { Vorrücken d. } \\
\text { Wassersäule } \\
\text { in je } 5 \mathrm{Min} .\end{array}$ & Bemerkungen. \\
\hline $\begin{array}{l}1 \\
2 \\
3 \\
4 \\
5 \\
6\end{array}$ & $\begin{array}{c}5,2 \mathrm{~mm} \\
7,8 " \\
11,4 " \\
8,8 " \\
7,0 " \\
6,6 "\end{array}$ & $\begin{array}{l}\text { Die Iris reagirt am Ende des Ver- } \\
\text { suches noch vollkommen normal; } \\
\text { die Kanüle noch etwas durchgängig. } \\
\text { Gesammtmenge des in } 30 \text { Minuten } \\
\text { secernirten h. a.: } 0,45 \mathrm{~cm} \text {. }\end{array}$ \\
\hline
\end{tabular}

Die Untersuchung des $\mathrm{h}$. a. nach 24stündigem Stehen ergiebt: Fibringerinnsel; Eiweiss in der defibrinirten Flüssigkeit bedeutend mehr als normal; Zucker.

V: Versuch.

Mittelgrosses Kaninchen; $0,15 \mathrm{ccm}$ Curarelösung injicirt; Einführung der Canüle ins linke Auge; Wasserdruck $20 \mathrm{~cm}$.

\begin{tabular}{|c|c|c|}
\hline $\begin{array}{l}\text { No. der } \\
\text { Beob- } \\
\text { achtung. }\end{array}$ & $\begin{array}{l}\text { Vorrücken d. } \\
\text { Wassersäule } \\
\text { in je } 5 \text { Min. }\end{array}$ & Bemerkungen. \\
\hline $\begin{array}{l}1 \\
2 \\
3 \\
4 \\
5 \\
6\end{array}$ & $\begin{array}{l}3,5 \mathrm{~mm} \\
6,5 \quad " \\
8,0 \quad " \\
6,0 \quad " \\
4,0 \quad " \\
4,0 "\end{array}$ & $\begin{array}{l}\text { Beim Einführen der Canüle waren } \\
\text { einige kleine Luftblasen in die vor- } \\
\text { dere Kammer mit eingedrungen. } \\
\text { Der Versuch wurde unterbrochen, } \\
\text { als Reizerscheinungen an der Iris } \\
\text { sich bemerklich machten. } \\
\text { Gesammtmenge des in } 30 \text { Minuten } \\
\text { secernirten h. a.: } 0,4 \mathrm{ccm} \text {. }\end{array}$ \\
\hline
\end{tabular}


Die Untersuchung nach 24stündiger Aufbewahrung des secernirten h.a. ergiebt: Fibringerinnsel; Eiweiss bedeutend mebr als normal; Zucker.

\section{VI. ₹ersuch.}

Mittelgrosses Kaninchen mit 0,15 Curarelösung vergiftet; Einführung der Canüle ins linke Auge. Wasserdruck: $20 \mathrm{~cm}$.

\begin{tabular}{|c|c|c|}
\hline $\begin{array}{c}\text { No. der } \\
\text { Beob- } \\
\text { achtung. }\end{array}$ & $\begin{array}{l}\text { Vorrïicken d. } \\
\text { Wassersäule } \\
\text { in je } 5 \text { Min. }\end{array}$ & Bemerkungen. \\
\hline $\begin{array}{l}1 \\
2 \\
3 \\
4\end{array}$ & $\begin{array}{l}7,5 \mathrm{~mm} \\
8,0 \quad " \\
5,0 \quad " \\
4,0 \quad "\end{array}$ & $\begin{array}{l}\text { Die Caniule am Ende des Versuchs } \\
\text { vollkommen verstopft. Gesammt- } \\
\text { menge des in } 20 \text { Minuten secernir- } \\
\text { ten h. a.: } 0,25 \mathrm{ccm} \text {. }\end{array}$ \\
\hline
\end{tabular}

Untersuchung des Secrets nach 24 Stunden ergiebt: Fibringerinnsel; Eiweiss mehr als normal; die Zuckerprobe der geringen Menge wegen nicht anzustellen.

VII. Versuch.

Grosses Kaninchen; $0,25 \mathrm{~cm}$ Curarelösung injicirt; Einführung der Canüle ins linke Auge, dabei Eintritt einiger Luftblasen. Wasserdruck $7,5 \mathrm{~cm}$.

\begin{tabular}{|c|c|c|}
\hline $\begin{array}{l}\text { No. der } \\
\text { Beob- } \\
\text { achtung. }\end{array}$ & $\mid \begin{array}{l}\text { Worrücken d. } \\
\text { Wassersäule } \\
\text { in } 1 \text { Minute. }\end{array}$ & Bemerkungen. \\
\hline $\begin{array}{l}1 \\
2 \\
3 \\
4 \\
5 \\
6 \\
7\end{array}$ & $\begin{array}{rl}12,2 \mathrm{~mm} & \\
4,3 " & \\
4,3 & \\
3,5 & \\
3,5 & " \\
3,5 & \\
1,8 & \end{array}$ & $\begin{array}{l}\text { Nach } 7 \text { Minuten die Canüle vollstän- } \\
\text { dig durch Gerinnsel verstopft. Im } \\
\text { Auge ein Gerinnsel am Einstichs- } \\
\text { ende der Kanüle liegend. Gesammt- } \\
\text { menge des in } 7 \text { Minuten secernirten } \\
\text { h. a.: } 0,35 \mathrm{com} \text {. }\end{array}$ \\
\hline
\end{tabular}

Die Untersuchung ergiebt 24 Stunden später: Massenhaftes Gerinnsel; massenhàft Eiweiss, unverhältnissmässig viel $\mathrm{mehr}$ als in den Versuchen IV-VI; Zucker.

\section{Versuch.}

Demselben Kaninchen wird die Canüle ins rechte Auge sofort nach Beendigung des eben beschriebenen Versuches eingeführt. Wasserdruck 7,5 cm.

\begin{tabular}{c}
\hline $\begin{array}{c}\text { No. der } \\
\text { Beob- } \\
\text { achtung. }\end{array}$ \\
\hline $\begin{array}{c}\text { Worrüicken d. je } 1 \mathrm{Min} . \\
\text { inssersäule }\end{array} \|$
\end{tabular}


Der H. aqueus d. Auges i. seinen Beziehungen z. Blutdruck u. Nervenreizung. 31

\begin{tabular}{|c|c|c|}
\hline $\begin{array}{c}\text { No. der } \\
\text { Beob- } \\
\text { achtung. }\end{array}$ & $\begin{array}{l}\text { Worrücken d. } \\
\text { Wassersäule } \\
\text { in je } 1 \text { Min. }\end{array}$ & Bemerkungen. \\
\hline $\begin{array}{r}3 \\
4 \\
5 \\
6 \\
7 \\
8 \\
9 \\
10 \\
11 \\
12\end{array}$ & $\begin{array}{l}3,3 \mathrm{~mm} \\
3,5 \quad " \\
3,0 \quad " \\
3,5 \quad " \\
3,5 \quad " \\
3,0 \quad " \\
1,5 \quad " \\
1,0 \quad " \\
1,0 \quad " \\
1,0 \quad "\end{array}$ & $\begin{array}{l}\text { Canüle nach } 12 \text { Minuten vollständig } \\
\text { verstopft; auch am intraocularen } \\
\text { Ende der Kanüle ein Gerinnsel. } \\
\text { Gesammtmenge des in } 12 \text { Minuten } \\
\text { secernirten h. a.: } 0,5 \mathrm{ccm} .\end{array}$ \\
\hline
\end{tabular}

Die Untersuchung nach 24 Stunden ergiebt: Massenhaft Fibrin, massenhaft Eiweiss, Zucker.

IX. Versuch.

Mittelgrosses Kaninchen, 0,2 ccm Curarelösung; Einführung der Canüle ins linke Auge. Wasserdruck $7,5 \mathrm{~cm}$.

\begin{tabular}{|c|c|c|}
\hline $\begin{array}{c}\text { No. der } \\
\text { Beobach- } \\
\text { tung. }\end{array}$ & $\begin{array}{l}\text { Vorrücken } \\
\text { in je } \\
5 \text { Minuten. }\end{array}$ & Bemerkungen. \\
\hline $\begin{array}{r}1 \\
2 \\
3 \\
4 \\
5 \\
6 \\
7 \\
8 \\
9 \\
10\end{array}$ & $\begin{array}{c}15,0 \mathrm{~mm} \\
10,0 " \\
4,5 " \\
7,0 " \\
8,5 " \\
8,0 " \\
5,0 " \\
4,0 " \\
2,0 " \\
1,5 "\end{array}$ & $\begin{array}{l}\text { Die Canüle am Ende des Versuchs } \\
\text { fast vollkommen durch Gerinnsel } \\
\text { verlegt. } \\
\text { Gesammtmenge des in } 5 \text { Minuten secer- } \\
\text { nirten h. a. } 0,65 \mathrm{ccm} \text {. }\end{array}$ \\
\hline
\end{tabular}

Das Secret zeigt nach 24stündigem Stehen bei der Untersuchung: Massenhäft Fibrin und Eiweiss; Zucker wie gewöhnlich.

$$
\text { X. Versuch. }
$$

Grosses Kaninchen; 0,25 Curarelösung injicirt; Einführung der Canüle ins linke Auge. Wasserdruck: $7,5 \mathrm{~cm}$.

\begin{tabular}{c|c}
\hline $\begin{array}{c}\text { No. der } \\
\text { Beobach- } \\
\text { tung. }\end{array}$ & $\begin{array}{c}\text { Vorrücken } \\
\text { der Wasser- } \\
\text { säule in je } \\
2 \text { Minuten. }\end{array}$
\end{tabular}




\begin{tabular}{|c|c|c|}
\hline $\begin{array}{l}\text { No. der } \\
\text { Beobach- } \\
\text { tung. }\end{array}$ & $\left|\begin{array}{c|}\text { Vorrücken } \\
\text { der Wasser- } \\
\text { säule in je } \\
2 \text { Minuten. }\end{array}\right|$ & Bemerkungen. \\
\hline $\begin{array}{r}5 \\
6 \\
7 \\
8 \\
9 \\
10 \\
11 \\
12\end{array}$ & $\begin{array}{l}3,5 \mathrm{~mm} \\
3,5 \quad " \\
3,0 \quad " \\
3,0 \quad " \\
2,5 \quad " \\
2,0 " \\
2,0 " \\
1,0 "\end{array}$ & $\begin{array}{l}\text { Gesammtmenge des in } 24 \text { Minuten } \\
\text { secernirten h. a. } 0,55 \mathrm{ccm} \text {. }\end{array}$ \\
\hline
\end{tabular}

Die Untersuchung des Secrets nach 24 Stunden ergiebt: Massenhaft Fibrin und Eiweiss; Zucker wie normal.

Der h.a. des rechten, nicht operirten Auges wird durch Punktion entleert und ergiebt nach Ablauf von 24 Stunden bei der Untersuchung Gerinnselbildung; vermehrten Eiweissgehalt; Zucker.

\section{Versuch.}

Grosses Kaninchen; durch Injection von $0,3 \mathrm{ccm}$ Curarelösung in die Jugularvene vergiftet; Finführung der Canüle ins rechte Auge: Wasserdruck $40 \mathrm{~cm}$, supranormal, es tritt folglich kein Steigen, sondern ein Sinken der Wassersäule ein :

\begin{tabular}{|c|c|c|}
\hline $\begin{array}{l}\text { No. der } \\
\text { Beobach- } \\
\text { tung. }\end{array}$ & \begin{tabular}{|c|} 
Sinken der \\
Wassersäule \\
in je \\
5 Minuten.
\end{tabular} & Bemerkungen. \\
\hline $\begin{array}{l}1 \\
2 \\
3 \\
4 \\
5 \\
6\end{array}$ & $\begin{array}{l}3,5 \mathrm{~mm} \\
3,5 n \\
3,0 " n \\
6,0 " \\
4,0 " \\
4,5 n\end{array}$ & $\begin{array}{l}\text { Nach } 25 \text { Minuten begann die Curare- } \\
\text { wirkung aufzuhören, das Thier } \\
\text { machte mit dem Auge Bewegungen } \\
\text { welche wegen der fixirten Stellung } \\
\text { der in letzterem befindlichen Canüle } \\
\text { zu einer erheblichen Zerrung und }\end{array}$ \\
\hline
\end{tabular}

dadurch Reizung des Auges Anlass geben mussten. Der Versuch wurde deshalb abgebrochen, der $h$. a. aus der vordern Kammer nach Tödtung des Thiers entleert. Bei der 24 Stunden später vorgenommenen Untersuchung fand ich: Kein Fibringerinnsel, wohl aber einen abnorm gesteigerten Eiweissgehalt, Zucker wie gewöhnlich. Der vermehrte Eiweissgehalt in diesem Versuche, bei welchem eher, analog dem Versuche III, eine Verminderung des Eiweisses zu erwarten stand, kommt wohl auf Rechnung der erwähnten mechanischen Reizung des Auges, welche auf das so leicht reizbare Kaninchenauge einwirkte. 
Der H. aqueus d. Anges i. seinen Beziehungen z. Blutdruck u. Nervenreizung. 33

XII. Versuch.

Grosses Kaninchen; $0,3 \mathrm{ccm}$ Curarelösung injicirt. Einführung einer Stichcanüle mit einfach horizontalem Glasrohr ins linke Auge. Druck in der vorderen Kammer also $=0$.

\begin{tabular}{|c|c|c|}
\hline $\begin{array}{c}\text { No. der } \\
\text { Beobach- } \\
\text { tung. }\end{array}$ & $\begin{array}{l}\text { Vorrücken } \\
\text { in } \\
1 \text { Minute. }\end{array}$ & Bemerkungen. \\
\hline $\begin{array}{r}1 \\
2 \\
3 \\
4 \\
5 \\
6 \\
7 \\
8 \\
9 \\
10 \\
11 \\
12 \\
13 \\
14 \\
15 \\
16 \\
17\end{array}$ & $\begin{array}{c}45,0 \mathrm{~mm} \\
5,0 \quad, \\
6,0 " \\
5,0 " \\
5,0 " \\
5,0 " \\
6,0 " \\
5,0 " \\
5,0 " \\
5,0 " \\
5,0 " \\
5,0 " \\
5,0 " \\
5,0 " \\
4,5 " \\
4,0 " \\
4,0 "\end{array}$ & $\begin{array}{l}\text { Der Versuch wird unterbrochen nach } \\
17 \text { Minuten, da das Thier sich zu } \\
\text { bewegen beginnt. Die Canüle noch } \\
\text { etwas durchgängig. } \\
\text { Gesammtmenge des in } 17 \text { Minuten } \\
\text { secernirten h. a.: } 0,8 \mathrm{ccm} \text {. }\end{array}$ \\
\hline
\end{tabular}

Die 24 Stunden später ausgeführte Untersuchung ergiebt: Fibrin und Eiweiss in solcher Menge, wie in keinem der früheren Versuche; Zucker wie gewöhnlich. -

Vergleichen wir nun die Ergebnisse der im Vorstehenden mitgetheilten Versuche, so folgt für den Eiweissgehalt der Kammerflüssigkeit zweifellos ganz allgemein, dass derselbe zunimmt, wenn der Druck in der vorderen Augenkammer herabgesetzt wird, dass derselbe also in der That mit der Differenz zwischen Blutdruck und Druck in der vorderen Kammer wächst. Die Eiweissproben, welche den verschiedenen Einzelfällen des unter wechselnden Druckverhältnissen secernirten $h$. a. entsprachen, zeigten deutliche Abstufungen von einer geringen flockigen Trübung, wie sie der normale b. a. giebt, bis $\mathrm{zu}$ einem massenhaften undurchsichtigen Niederschlag, wie in Versuch II, VII - X, besonders aber in Versuch XII. Ausserdem liefern die Versuche auch einen deutlichen Beweis für die Abhängigkeit der Quantität des h. a. vom Blutdrucke. Während hei den Versuchen I und IV-VI bei einem Drucke von $20 \mathrm{~cm}$ Wasser in der Minute eine mittlere Menge von $0,013 \mathrm{ccm}$ h. a. secernirt wurde, erreichte in den Versuchen II und VII-X, E. Pfiüger, Archiv f. Physiolıgie, Bd, XxIII, 
wo die vordere Kammer sich unter dem geringen Drucke einer $7,5 \mathrm{~cm}$ hohen Wassersäule befand, die Ausscheidung von h. a. in der Minute den Mittelwerth von 0,037 ccm, also fast den dreifachen Betrag, und in Versuch XII, wo der Druck in der vorderen Kammer gleich Null war, sogar den von $0,05 \mathrm{ccm}$. Die Schnelligkeit, mit welcher die Verstopfung der Canüle durch Gerinnselbildung erfolgt, hängt erstens von der Menge des ausgeschiedenen Fibrins ab; der Zeitpunkt, zu welchem die gänzliche Sperrung des Abflussrohres in unsern Versuchen stattfindet, fällt dementsprechend um so früher, je geringer der Druek in der vorderen Kammer, je grösser also die Druckdifferenz bemessen war, unter welcher die Secretion des h. a. vor sich gehen sollte. Zweitens hängt der frühere oder spätere Eintritt der Cantilenverstopfung jedoch auch von der zufälligen Configuration und Lage des Gerinnsels ab, so dass bei Secretion unter gleichen Druckverhältnissen der Eintritt des h. a. in die Röhre bald früher bald später behindert wurde.

Hiermit schliessen die Beobachtungen ab, welche von mir betreffs der Frage iuber die zwischen Blutdruck und ehemischer Beschaffenheit des h. a. bestehenden Beziehungen gesammelt worden sind und wohl zur Genüge die Unzulänglichkeit des früher citirten Dogiel'schen Ausspruchs beweisen. Einer besonderen Besprechung bedürfen indessen noch zwei Erfahrungen, welche ich bei Gelegenheit der oben mitgetheilten Versuche gemacht habe, deren eine sich auf den Einfluss der Curarevergiftung auf die Fibrinproduction in der vorderen Kammer bezieht, deren andere von einem bis jetzt unbekannt gebliebenen Zusammenhang der Kammerwasserausscheidung beider Augen handelt.

Es war mir bei einigen Versuchen, welche nur das Ange der einen Seite betrafen, aufgefallen, dass der h. a. des anderen nicht operirten Auges eine auffällige Vermehrung seines Eiweissgehaltes wahrnehmen liess und ferner, ebenfalls ganz abweichend von der Norm, nach mehrstündigem Stehn ein Fibrincoagulum ausschied. Eine Erklärung für diese Thatsache, auf welche ich in Versuch X ausdrücklich aufmerksam gemacht habe, konnte nach zwei Richtungen gesucht werden. Einmal liess sich denken, dass die abnorme Beschaffenheit des $h$. a. eine unvorhergesehene Folge der Curarevergiftung wäre, andererseits bestand aber auch die Möglichkeit, dass der operative Eingriff auf dem einen Auge mit seinen die normale Secretion ändernden Folgen ähnliche Wirkungen, obschon 
Der H. aqueus d. Auges i. seinen Beziehungen z. Blutdruck $u$, Nervenreizung . 35

schwächeren Grades, auch in dem Ange der anderen Seite ausgelöst haben könnte. Wie sich bei näherer Prüfung der in Rede stehenden Angelegenheit herausstellte, kommen in der That beide angedeuteten Momente in Betracht.

Einfluss der Curarevergiftung auf den h. a.

Um den Einfluss der Curarevergiftung auf die chemische Zusammensetzung der Augenflüssigkeit allein für sich schätzen zu können, musste natiirlich jedwede andere Reizung des Anges vermieden werden. Ich beschränkte mich daher darauf, in allen hierher gehörigen Versuchen die vena jugularis externa blosszulegen, in dieselbe die zur Narcotisirung erforderliche Curaremenge zu injiciren, sodann künstliche Athmung einzuleiten und eine Stunde lang ohne Unterbrechung fortzusetzen. Hierauf wurde das Thier durch Sistirung des Lufteinblasens getödtet, der h. a. nach erfolgtem Tode entleert und nach 24stündigem Stehen auf Fibrin- und Eiweissgehalt untersucht. Das Ergebniss in allen von mir angestellten Experimenten war, dass bei mit Curare vergifteten Kaninchen eine, wenn auch geringe Ausscheidung von Fibrin neben gleichzeitiger Vermehrung des normalen Eiweissgehalts zu constatiren ist. Um endlich noch eine mögliche Reiznng des bei der Curarevergiftung offen stehenden Auges durch Staubpartikelchen oder Eintrocknung auszuschliessen, richtete ich einige Versuche derart ein, dass ich das eine der Augen durch Lidsuturen vernähte, ohne jedoch ein anderes Resul tat als das schon angegebene $\mathrm{zu}$ erzielen; denn auch hier war Fibrin und eine Steigerung des Eiweissgehaltes im h. a. beider Augen unverkennbar vorhanden. Man wird sich folglich dem Schlusse nicht entziehen können, dass diese abnorme Beschaffenheit des $h$. a. durch die Curarevergiftung bedingt ist, welche wahrscheinlich durch Aenderung der Circulationsverhältnisse im Auge (Erregung gefässdilatirender Nerven) für die Fibrinproduction und Eiweissvermehrung günstige Verhältnisse schafft. Selbstverständlich wird hierdurch das Ergebniss unserer Versuche zur Ermittlung des zwischen Eiweissgehalt des h. a. und Blutdruck bestehenden Abhängigkeitsverhältnisses in keiner Weise berührt, da bei denselben alle Thiere in gleicher Weise curarisirt wurden und also zur vergleichsweisen Feststellung der gesuchten Relation zweifellos verwerthbar waren. 
Wechselbeziehungen beider Augen hinsichtlich ihrer secretorischen Vorgänge.

Es ist zwar eben nachgewiesen worden, dass an dem Auftreten von Fibrin in der Kammerflïssigkeit neben gleichzeitiger Vermehrung des Eiweissgehalts auf beiden Augen, von denen aber nur das eine durch den operativen Eingriff in wesentlich veränderte Bedingungen gebracht worden war, das gleichzeitige Bestehn der Curarevergiftung sicherlich von Einfluss gewesen sein kann. Damit sind wir aber noch keineswegs berechtigt, die andere zur Erläuterung des in Rede stehenden Vorgangs aufgestellte Hypothese, welche von der Annahme einer functionellen Wechselbeziehung in den Ernährungsprocessen beider Augen ausging, fiir definitiv abgewiesen anzusehen. Vielmehr bedarf dieselbe einer besonderen Prüfung, der ich sie in folgender Art unterzogen habe. Zunächst ätzte ich bei sonst vollkommen gesunden Kaninchen die Cornea des einen Auges am Corneoseleralrande mit Höllenstein in Substanz, entfernte, um unbeabsichtigte weitere Aetzungen zu verhüten, den Ueberschuss des Aetzmittels durch Ueberrieselung mit $1 \%$ Kochsalzlösung, um schliesslich nach Ablauf von $1 / 2-1$ Stande das Thier zu tödten und den h. a. sodann jedem Auge besonders mittelst einer feinen, aufs sorgfältigste gereinigten Pravaz'schen Spritze zu entnehmen. Die in ein schmales Sammelgefäss ïbergefüllte Flüssigkeit wurde 24 Stunden ruhig stehen gelassen, damit etwaige Fibringerinnsel sich vollständig absetzen könnten. Das Ergebniss, zu welchem ich auf dem bezeichneten Wege gelangte, war ebenso überraschend als constant. Ausnahmslos enthielt der h. a. des geäzten Auges Fibrin und massenhaft Eiweiss, ebenso, wenn auch in geringerer Menge derjenige des unversehrt gebliebenen. Von andern Thieren habe ich nur noch Katzen dem gleichen Experiment unterworfen und bin auch hier zum gleichen Resultate wie beim Kaninchen gelangt.

Um die Aetzung bei Katzen vorzunehmen, wurden dieselben durch Chloroform betäubt, nach ihrem Wiedererwachen noch eine Stunde leben gelassen, dann durch erneute Chloroforminhalationen getödtet; der entleerte h. a. wurde in der oben erwähnten Weise behandelt. Fibrin und Eiweissvermehrung waren auch in dem gesunden Auge stets deutlich nachweisbar. 
Suchen wir nun die Frage zu beantworten, auf welchem Wege diese sympathische Vermehrung des Eiweissgehalts und Ausscheidung der Fibringeneratoren in beiden Augen zu Stande kommt, in welches Gebiet physiologischer oder pathologischer Prozesse dieser lsurz als Sympathie zu bezeichnende Vorgang einzureihen sein dürfte, so ist vor allem klar, dass eine ungeachtet der relativen Entlegenheit des Reizes so schnell eintretende Secretionsänderung nur durch das Nervensystem vermittelt sein kann.

Absolut undenkbar erseheint mir, dass eine etwaige durch die Reizung auf dem einen Auge hervorgerufene Entzündung sich in so kurzer Zeit auf das andere Auge fortgepflanzt haben könnte. Halten wir nun daran fest, dass nur nervöse Einflisse die Vermittler der geschilderten sympathischen Vorgänge beider Augen sein können, so wird unsere Aufmerksamkeit naturgemäss auf die am. Orte der Reizung, also am Corneoseleralrande, verlaufenden nn. ciliares, deren Fasern bekanntlich dem ramus ophthalmicus n. trigemini entstammen, gelenkt, und damit zu der weiteren Frage Anlass geboten, in wieweit der ramus ophthalmicus des Quintus an dem ganzen Vorgange betheiligt ist. Unsere Aufgabe wird es also sein müssen, das chemische Verhalten der Augenflüssigkeit nach Durchschneidung beziehungsweise Reizung des ram. ophthalm. oder des Trigeminus sèlbst einer näheren Priffung zu unterwerfen. Die operativen Eingriffe, welche hierzu erforderlich sind, können bekanntlich an verschiedenen Stellen des Quintusverlaufes vorgenommen werden: entweder am Ursprung des Trigeminus in der medulla oblongata, oder an dem alle drei Aeste umfassenden Stamme, oder endlich am Augenaste allein.

Obgleich Versuche der letzterwähnten Kategorie zur Entscheidung der angeregten Frage genügen würden, habe ich dennoch neben der intracraniellen Durehtrennung des ramus ophthalmicus auch diejenige der hintereu Quintuswurzeln in der medulla oblongata wiederholt ansgefuhrt und ihre Wirkung auf die chemische Beschaffenheit des h. a. geprüft. Als Anhaltspunkte für die gelungene Ausführung der übrigens nur an Kaninchen unternommenen Operation dienten mir die sofort eintretende vermehrte Spannung des Bulbus, die starke Verengerung der Pupille und die freilich zuweilen nur partielle Anaesthesie der Cornea. Ausserdem wurde selbstverständlich auch nicht versäumt, die Natur des Eingriffs nach dem Tode des Thieres dureh die Section zu controliren. Dieses 
vorausgeschickt lasse ich jetzt die Protocolle eines Theils der von mir angestellten Versuche folgen.

$$
\text { Versuch I, II, III. }
$$

Intracranielle Durchschneidung des ramus ophthalmicus trigemini links; Cornea sofort anästhetisch, Pupille verengt. Tod nach 1 Stunde durch Nackenstich.

Die Untersuchung des beiden Augen getrennt entnommenen h. a. ergiebt nach 24 .Stunden:

h. a. des linken Auges (operirte Seite):

Massenhaft Fibrin und Eiweiss.

h. a. des rechten Auges:

Viel Fibrin, bedeutend vermehrter Eiweissgehalt.

\section{Versuch IV.}

Intracranielle Durchschneidung des ramus ophthalmicus trigemini linkerseits mit vollkommenem Erfolg. Tod nach 24 Stunden durch Nackenstich.

Resultat:

b. a. des linken Auges (operirte Seite):

Viel Fibrin und Eiweiss.

h. a. des rechten Auges:

Geringes Gerinnsel, Eiweiss etwas vermehrt.

\section{Versuch V.}

Intracranielle Durchschneidung des ramus ophthalmicus trigemini mit vollkommenem Erfolg. Aetzung der linken anästhetischen Cornea 24 Stunden später; Tod, 1 Stunde nach der Aetzung, durch Nackenstich.

Resultat:

h. a. des linken Auges (operirte Seite):

Starke Gerinnselbildung, erhebliche Eiweissvermehrung.

h. a. des rechten Auges:

Wenig Gerinnsel, etwas vermehrter Eiweissgehalt.

Versuch VI u. VII.

Versuch den ramus ophthalmicus trigemini linkerseits intracraniell zu durchschneiden mit unvollkommenem Erfolg, da die anfangs stark verminderte Sensibilität der Cornea bald fast ganz wiederkehrt. Tödtung 1 Stunde später durch Nackenstich. Die Section ergiebt nur eine Quetschung des Trigeminus. Im h. a. beider Augen findet sich nach mehrstündigem ruhigem Stehen Abscheidung eines Fibrincoagulums und Vermehrung des Eiweissgehalts. 
Der H. aqueus d. Auges i. seinen Beziehungen z. Blutdruck u. Nervenreizung. 39

Versuch VIII, IX.

Intracranielle Durchschneidung des ramus ophthalmicus trigemini linkerseits mit vollkommenem Erfolge. Das linke Auge zugenäht. Nach 10 Tagen wird die vollkommen anästhetische und etwas getrübte linke Cornea geätzt. Tödtung 1 Stunde später durch Nackenstich.

Resultat:

h. a. des linken Auges:

Massenhaft Fibrin und Eiweiss.

h. a. des rechten Auges:

Geringes Gerinnsel, geringe Vermehrung des Eiweissgehalts.

Versuch X.

Intracranielle Durchschneidung des ramus ophthalmicus trigemini linkerseits mit vollkommenem Erfolge. 10 Tage später wird das Thier bei vollkommen anästhetischer etwas trüber Cornea des linken, durch Suturen verschlossen gewesenen Auges mittelst Chloroforminhalationen getödtet.

Resultat:

h. a. des linken Auges:

Massenhaft Fibrin und Eiweiss.

h. a. des rechten Auges:

Geringes Gerinnsel; geringe Vermehrung des Eiweissgehalts.

Versuch XI.

Operation wie im Versuch $\mathrm{X}$. Cornea vollkommen vereitert nach 10 Tagen. Resultat wie in Versuch $\mathrm{X}$.

Versuch XII, XIII, XIV, XV.

An einem Kaninchen wird die membranà atlanto-occipitalis freigelegt und eröffnet, die cerebrospinale Flüssigkeit abgelassen, dann die linke Hälfte der medulla oblongata oberhalb des calamus scriptorius durchtrennt. Die erhöhte Spannung, Verengerung der Pupille und Anästhesie der Cornea auf dem linken Auge beweist, dass die beabsichtigte Durchtrennung der hinteren Quintuswurzel gelungen ist. Tod der Thiere in Versuch XII bald nach der Operation, in Versuch XIII 1 Tag, Versuch XIV 3 Tage, Versuch XV 4 Tage nach der Operation. Die Untersuchung des beiden Augen jedesmal getrennt nach dem Tode entnommenen h. a. nach mehrstündigem Stehen ergiebt das folgende übereinstimmende Resultat:

h. a. des linken Auges (operirte Seite):

Reichliches Gerinnsel, bedeutende Vermehrang des Eiweissgehalts.

h. a. des rechten Auges :

Gerinnsel, aber weniger beträchtlich als auf der operirten Seite, Eiweiss gegen die Norm vermehrt. 
Fassen wir nun das Ergebniss dieser Versuche kurz zusammen, so gelangen wir zu folgenden Sätzen: Nach intracranieller Durchschneidung oder Reizung (VI, VII) eines ramus ophthalmicus n. trigemini oder der hinteren Wurzeln desselben in der medulla oblongata finden wir nach $1 / 2-1$ Stunde beiderseits eine deutliche Vermehrung des Eiweissgehalts mit abnormer Fibrinproduction in der vorderen Augenkammer, und zwar in stärkerem Maasse auf dem Auge der operirten Seite. Diese abnorme Beschaffenheit des h. a. hält mehrere, in einigen Fällen bis zu 10 Tagen, an, nimmt jedoch im Laufe der Zeit mehr und mehr ab. War der Trigeminus auf einer Seite durchschnitten, so wurde durch Aetzung des entsprechenden Auges eine weitere Zunahme des an und für sich schon vermehrten Eiweissgehalts und der Fibrinausscheidung im anderen Auge nicht mehr erzielt (vergl. V, VIII, IX). - Der Schluss, den wir aus diesen Ergebnissen zu ziehen berechtigt sind, ist also folgender: Es besteht zwischen den vom n. trigeminus vermittelten Innervationsvorgängen und der chemischen Beschaffenheit des h. a. irgend ein directer oder indirecter Zusammenhang, die Bahnen des Trigeminus sind es, durch welche die Secretionssympathicen beider Augen vermittelt werden.

Dieses festgestellt bleibt uns noch übrig za untersuchen, welcher Natur die von so eigenartigen Wirkungen begleiteten Innervationsvorgänge des Trigeminus sind. Die Functionen des ramus ophthalmicus n. trigemini sind bekanntlich von vielfacher Art, ausser sensiblen Nervenfasern fuihrt er dem Auge noch vasodilatatorische, nach manchen Autoren auch motorische für den sphincter iridis, trophische für die Cornea und endlich secretorische Fasern für die Drüsen der Orbita zu. Von diesen functionell so verschiedenen Elementen des Quintus können meines Erachtens hier nur die vasodilatatorisch wirkenden, deren Vorhandensein nach den Untersuchungen v. Hi p pels und Grünhagens die auf Reizung des Trigeminusstammes eintretende excessive intraoculare Drucksteigerung mit bedingt, in Betracht kommen. Auf den vorliegènden Fall bezogen hätten wir uns also vorzustellen, dass in Folge einer durch die oben beschriebenen Eingriffe hervorgerufenen activen Gefässerweiterung die Verhältnisse für dic Filtration des Eiweisses und der Fibringeneratoren sich günstiger gestalten, und mithin direct sowohl zu einer Vermehrung der Eiweissausscheidung als auch zur Fibrinproduction im h. a. Anlass geben. 
Hiermit ist ausgesprochen, dass die fraglichen Vorgänge auf einem gesteigerten Erregungszustand des Trigeminus beruhen, eine Annahme, der sich die Versuche VI und VII, bei welchen zweifellos nur eine Reizung des ramus ophthalmicus statt hatte, auf die bequemste Art fügen. Einer besonderen Erläuterung bedarf es aber noch, ob die von mir gemachteVoraussetzung auch für diejenigen Versuche in Anspruch genommen werden kann, bei welchen der Quintus in seinem Verlaufe oder Ursprunge durchtrennt wurde, also Bedingungen hergestellt wurden, unter denen sonst Lähmung nervöser Einflüsse einzutreten pflegt. Kurz es handelt sich jetzt um die Entscheidung der Frage, ob die Continuitätstrennung des Quintus durch Aufhebung bestimmter Nervenwirkungen ihren modificirenden Einfluss auf die ehemische Beschaffenheit des h. a. ausiibt, oder ob wir dem durch die Durchschneidung selbst gegebenen und sie eventuell längere, Zeit überdauernden mechanischen Reize die entsprechende Bedeutung beizulegen haben. Man erkennt leicht, dass die eben aufgeworfene Frage durch das Ergebniss derjenigen Versuche beantwortet ist, welche ganz zweifellos als Reizversuche angesehen werden können und entweder nur auf einer offenbaren Reizung des Quintus (vergl. Versuche VI, VII), oder auf einer chemischen oder mechanischen Reizung der Hornhaut beruhen. Denn wenn wir berechtigt sind jene Eingriffe als Reizmittel für vasodilatatorische Trigeminusfasern aufufassen, so ist wegen der Gleichartigkeit der Folgezustände dieses auch hinsichtlich der intracraniellen Trigeminusdurchschneidung gestattet. Wäre die Wirkung der letzteren die Folge einer Neuroparalyse, so müsste sie derjenigen, die durch die offenbaren Reizversuche erzielt wurde, entgegengesetzt sein. Aber es sprechen auch noch Gründe anderer Art dafür, dass die Veränderungen, welche die Zusammensetzung des h. a. nach Trigeminusdurchschneidung erleidet, als Reizerscheinungen angesehen werden muissen. Erstens finden wir einen solchen Grund in dem Umstande, dass die Fibrinausscheidung und die Vermehrung des Eiweissgehalts im h. a., welche die erwähnte Operation hervorruft, vorubbergehender Natur sind. Dies geht aus Versuchen hervor, bei welchen es gelingt, durch die Lidnaht jeder entzündlichen Veränderung der anästhetischen Cornea vorzibeugen. Die abnorme Beschaffenheit des h. a. nimmt nach einigen Tagen immer mehr ab, und kann schliesslich ganz verschwinden.

Dieselbe auf Erregungen zu beziehen, welche von der intra- 
craniellen Schnittstelle am Nervenstumpf ausgelöst werden, nicht aber als Folge einer totalen Neuroparalyse anzusehen, ist also unumgänglich nothwendig. Ein zweites Moment, welches für unsere Auffassung spricht, liegt aber in der Thatsache der von mir wahrgenommenen Secretionssympathie beider Augen. Die beste Vorstellung, welche man sich über das Zustandekommen derselben zu bilden vermag, dürfte wohl die folgende sein: Die Reizungen, welche durch das Anätzen des Cornealrandes in den nn. ciliares oder durch die operativen Eingriffe in den intracraniellen Verlauf des Quintus oder seines Ursprunges bedingt werden, geben theils indirect auf reflectorischem Wege durch die jedenfalls mit betroffenen sensiblen Trigeminusfasern, theils, wie in den letzten beiden Fällen anzunehmen ist, auch direct zu einer Erregung der zweifellos im ramus ophthalmicus n. trigemini enthaltenen vasodilatatorischen Fasern Anlass. Die auf dem Wege des Reflexes zu Stande gekommenen Erregungen der gefässerweiternden Trigeminusfasern bleiben aber nicht auf die Seite des reizenden Eingriffs beschränkt, sondern irradiiren auch in der medulla oblongata auf die entsprechenden Fasern des andersseitigen Trigeminus.

Der Voraussetzung, von welcher wir das Auftreten von Fibrin und die abnorme Steigerung des Eiweissgehalts im $h$. a. abhängig machten, sehen wir also in beiden Augen entsprochen. Dass die Reaction des primär afficirten Auges stärker ausfällt, als diejenige des secundär in Mitleidenschaft gezogenen zweiten Auges, ist wohl leicht erklärlich. - Begreiflicherweise steht und fällt die eben gegebene Erklärung für die an Katzen und Kaninchen beobachtete Secretionssympathie beider Augen mit der von mir befürworteten Annahme, dass nicht nur die Aetzung der Trigeminusenden in der Hornhant, sondern auch die Durchschneidung. des Quintus an seinem Ursprunge oder in seinem Stamme einen längere Zeit anhaltenden Reizzustand wenigstens eines Theiles seiner Fasern hervorzurufen vermöge.

Wären wir gezwungen, den intracraniellen Durchtrennungen einen ausschliesslich lähmenden Einfluss zuzuerkennen und die Secretionsanomalieen des h. a. für den Ausdruck eines paralytischen Zustandes zu halten, so würden wir keine Möglichkeit sehen, das zwischen beiden Augen bestehende Abhängigkeitsverhältniss zu. denken. Denn so leicht man sich auf Grund geläufiger physiologischer Vorstellungen ein Bild davon machen kann, wie ein ner- 
Der H. aqueus d. Auges i. seinen Beziehungen z. Blutdruck u. Nervenreizung. 43

vöser Reizvorgang centripetal fortgeleitet und auf symmetrisch gelegene Nervenursprünge im Centrum uibertragen werden kann, so unmöglich scheint es, einem Lähmungszustand peripherer Nerven die gleiche Verbreitungsfähigkeit zuzuschreiben. Davon, dass sich eine im durchschnittenen Nerven entstandene Degeneration oder Entzündung centralwärts fortgepflanzt haben möchte, kann hier, wo die Wirkungen dem ursächlichen Eingriffe fast momen$\tan$ folgen, füglich keine Rede sein.

Findet nun aber auch diese von mir gegebene Erklärung, welche den beobachteten Erscheinungscomplex auf eine Reizung gefässdilatirender Nerven zuriickführt, in dem eben angeführten Momente eine bedeutende Stïtze, so soll damit doch nicht gesagt sein, dass sie die einzig mögliche wäre und soll ebensowenig der hypothetische Character derselben verhehlt werden. Ferner soll hier nur beiläufig angedeutet aber nicht genauer angeführt werden, wie sehr nahe es läge, die von mir beobachtete Sympathie beider Augen in Beziehung zu der sogenannten sympathischen Ophthalmie zu bringen. Dagegen halte ich es für angemessen, zum Schlusse meiner Arbeit die von mir ermittelten Thatsachen, wie folgt, zusammenzustellen.

\section{Resultate.}

1. Der vollkommen normale h. a. enthält stets Eiweiss und Zucker, aber keine Fibringeneratoren. Der Zucker verschwindet nach dem Tode innerhalb 24-48 Stunden, wenn der h. a. in ungestörter Berührung mit den Bulbusgeweben bleibt.

2. Der Glaskörper ist eiweissreicher als der h. a. und enthält ebenfalls Zucker, welcher bezuiglich seines Verbleibens im todten Auge das gleiche Verhalten zeigt, wie derjenige des h. a.

3. Fibrinproduction in der vorderen Kammer wird hervorgerufen durch Aenderungen in den Druckverhältnissen des Auges und durch Reize, welche das Auge treffen; letztere bewirken Gefässdilatation.

4. Die Quantität des Eiweisses im h. a. wächst mit der Differenz zwischen Blutdruck und Druck in der vorderen Augenkammer.

5. Ebenso wie chemische und mechanische Reizung des Auges, fuhrt auch die Curarevergiftung bei Einleitung künstlicher 
Athmung zu einer Ausscheidung der Fibringeneratoren im h. a. und zu einer abnormen Vermehrung des Eiweissgehaltes.

6. Der Trigeminus führt dem Auge vasodilatatorische Fasern zu, deren Reizung gesteigerten Blutzufluss zum Auge mit consecutiver Ausscheidung der Fibringeneratoren und Steigerung des Eiweissgehaltes im $h$. a. hervorruft.

7. Reize, welche die nn. ciliares resp. den Trigeminus der einen Seite treffen, rufen zu gleicher Zeit Erweiterung der Gefässe auf dem Auge der anderen Seite mit allen ihren Folgen hervor.

Zum Schluss nehme ich Gelegenheit meinem hochverehrten Lehrer Herrn Prof. Dr. A. Gruenhagen für die freundliche Unterstïtzung bei dieser Arbeit meinen besten Dank abzustatten.

\section{Ueber das}

Verhalten des Glycogens und der Milchsäure im Muskelfleisch mit besonderer Berücksichtigung der Todtenstarre.

Von

Prof. Dr. Rudolf Boehm

in Dorpat.

Die im Nachstehenden mitzutheilenden Untersuchungen verfolgen den Zweek, die gegenwärtig herrschenden Ansichten über das Verhalten des Glyeogens und der Milchsäure im frischen und todtenstarren Muskel einer Experimentalkritik zu unterwerfen. Es sollte durch diese Vorarbeit die Grundlage geschaffen werden fur die weitere Fortsetzung der Untersuchungen über den Kohlehydratstoffwechsel, welche ich in Gemeinschaft mit F. A. Hoffmann (Arch. f. exp. Path. u. Pharm. Bd. VIII. IX.) veröffentlicht habe. Die bereits vor $2^{1 / 2}$ Jahren begonnene Arbeit hat in Folge unerwarteter Schwierigkeiten einen grossen Zeitaufwand erfordert. 